\title{
Clinical and immunological evaluation of efficacy of use in the dynamics of topical application of FarGALS in patients in the process of adaptation to complete removable plate prosthesis depending on age
}

\author{
Akbarov Avzal Nigmatullaevich \\ Doctor of Medical Sciences, Associate professor of the department of orthopedic stomatology \\ Dadabaeva Mukhlisa Ulugbekovna \\ Candidate of Medical Sciences, Associate professor of the department of orthopedic stomatology
}

\section{Usmanxodjayeva Diyoraxon Rovshan qizi}

Master of the department of orthopedic stomatology

\section{Email address:}

akbarov@mail.ru (Akbarov Avzal Nigmatullaevich)

To cite this article:

Akbarov Avzal Nigmatullaevich, Dadabaeva Mukhlisa Ulugbekovna, Usmanxodjayeva Diyoraxon Rovshan qizi. Clinical and immunological evaluation of efficacy of use in the dynamics of topical application of FarGALS in patients in the process of adaptation to complete removable plate prosthesis depending on age. Journal of research in health science. Vol. 1, No. 2, 2018, pp. 60-66. DOI 10.26739/2523-1243

\section{doi http://dx.doi.org/10.26739/2523-1243/-2018-1-2-10}

\begin{abstract}
: the author considers the complications arising from prosthetics with complete removable dentures. The article analyzes the effectiveness of the FarGALS preparation in elderly people. To obtain reliable results on the state of the oral mucosa, microbiological and immunological methods of diagnosis were used. It has been revealed that the use of FARGALS as an antiseptic for a prosthesis, within 30 days after prosthetics with complete removable dentures, has an antibacterial effect restoring the patient's immune protection.
\end{abstract}

Keywords: complete removable plate, the drug FarGALS, local immunity, elderly age.

The problem of adaptation to complete removable plate prosthetics is acute fordental specialists. The negative impact of prosthetics on the condition of prosthetic bed, the function of the salivary glands, immunological reactivity, microbiological diversity of oral cavity and insufficient quality of prosthetics 
manufacture and design features contribute the problem. It is especially relevant to the elderlypatients;at who, along with the complete loss of dental rows, the adaptive capabilities of the body, including the oral cavity, are sharply reduced and do not positively resist the negative effects associated with removable prosthesis.

Unreasonable and uncontrolled use of chemotherapy leads to the formation of strains with resistance to drugs. This can be avoided by using antiseptic drugs that have a broad antibacterial spectrum and do not induce microbial resistance.

Further application of the medicinal forms of antiseptics for topical application is undoubtedly a very promising direction, as it allows to change the nature of the effect on the humoral and cellular inflammation factors in the adaptation period while using complete removable plate prostheses.

The particular interest from the point of view of the use of new medicines forms for the use of complete removable plate prostheses lays in the influence of FarGALS on local immunity and bacteriological parameters of the oral cavity of elderly patients using complete removable plate prostheses and on the process of adaptation to them. (The drug FarGALS is included in the pharmacotherapeutic Group: antiseptic wound-healing agents).

Patients were divided into the following groups:
- the first group (1st group - 23, 2nd group-52, 3rd group-45, 4th group-23) -the patients who formed the main group treated with FarGALS.

- the second group (1st group 19, 2nd group-43, 3rd group-37, 4th group-16) -patients who formed the control group, who were treated with the traditional method.

Patients of the main group after the meal and at bedtime performed the processing of removable plate prostheses and during the day 3-4 times rinsed by diluting FarGALS with distilled water 1:4.

At the background of the treatment, immunological and microbiological studies were conducted in dynamics (with admission, after treatment, day 15 , after 30 days).

As has been shown in elderly patients with complete absence of teeth, at the seeking orthopedic care, there is a violation of local immunity in the form of deficiency of FAN, FCH, lysozyme, secretory sIgAin the oral cavity, depending on the age aspect. In this connection, it is of interest to study the effectiveness of the current therapy of impaired local immunity in the process of adaptation to removable prostheses, depending on the method of treatment for these body indices. The results of the study are presented in Table 1.

Level of content of local immunity parameters in mixed saliva in patients of the 1st group (from 40 to 59 years) with orthopedic treatment in dynamics. 
Akbarov A.N., Dadabaeva M.U., Usmanxodjayeva D.R. Clinical and immunological evaluation of efficacy of use in the dynamics of topical application of FarGALS in patients in the process of adaptation to complete removable plate prosthesis depending on age

Table 1.

\begin{tabular}{|c|c|c|c|c|}
\hline No. & Indicators & Baselines & 15 daysaftertreatment & 30 daysaftertreatment \\
\hline \multirow{4}{*}{ Controlgroup } & FAN in $\%$ & $52.8 \pm 0.82$ & $54.4 \pm 2.8$ & $46.6 \pm 2.26 * \bullet$ \\
\hline & FH & $4.06 \pm 0.82$ & $4.12 \pm 0.21$ & $3.95 \pm 0.17$ \\
\hline & $\begin{array}{c}\text { Lysozyme } \\
\mathrm{mg} / \mathrm{ml}\end{array}$ & $19.3 \pm 0.46$ & $28.8 \pm 0.86 * *$ & $19.5 \pm 0.62 \bullet$ \\
\hline & $\mathrm{SIgA \mu g} / 1$ & $199 \pm 6.0$ & $226 \pm 8.3 *$ & $188 \pm 9.2 \bullet$ \\
\hline \multirow{4}{*}{$\begin{array}{l}\text { Basic } \\
\text { Group }\end{array}$} & FAN in $\%$ & $52.8 \pm 0.82$ & $60.4 \pm 1.9^{* * 0}$ & $52.0 \pm 1.24 \bullet^{\circ}$ \\
\hline & $\overline{\mathrm{FH}}$ & $4.06 \pm 0.82$ & $4.83 \pm 0.19 * * 0$ & $4.28 \pm 0.17 \bullet$ \\
\hline & $\begin{array}{c}\text { Lysozyme } \\
\mathrm{mg} / \mathrm{ml}\end{array}$ & $19.3 \pm 0.46$ & $32.2 \pm 0.90 * * \mathrm{o}$ & $20.4 \pm 0.58$ •• \\
\hline & SIgA $\mu \mathrm{g} / 1$ & $199 \pm 6.0$ & $302 \pm 7.8 * *$ o o & $205 \pm 7.9 \bullet \bullet$ \\
\hline
\end{tabular}

Note: The reliability of the difference from the original $(* *-\mathrm{P}<0.001$ and $*-\mathrm{P}<0.05)$; From the data of 15 days $(\bullet-\mathrm{P}<0.001$ and $\bullet-\mathrm{P}<0.05)$ and monitoring data $\left(^{\circ}{ }^{\circ}-\mathrm{P}<0.001\right.$ and ${ }^{\circ}$ -

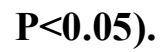

As can be seen from the data of Table 1. In patients of group 1 (from 40 to 59 years after the start of traditional therapy), in patients receiving treatment with removable prostheses and oral rinsing, there were insignificant positive shifts in FAN, lysozyme and sIgA values in local immunity on the 15 th day of the study and were respectively $54.9 \pm 1.1 \%$; $22.7 \pm 0.83 \mathrm{mg} / \mathrm{ml}$ and $226 \pm 8.3 \mu \mathrm{g} / \mathrm{l}$. It can be seen that only the lysozyme and sIgA values are significantly higher in comparison with the initial indices $(\mathrm{P}$ $<0.001$ and $\mathrm{P}<0.05)$, respectively. However, on day 30 of the study, the local immunity indices of the $1^{\text {st }}$ group of patients examined were below the normative value.

A very different picture was observed in Group 1 patients (from 40 to 59 years after initiation of therapy (local treatment by FarGALS) on the day 15.a significant increase was observedon the part of the phagocytic index of neutrophils: if in the given group, on admission, the FAS was averaged $52.8 \pm 0,82 \%$, in the process of treatment with FarGALS, this index averaged $60.4 \pm 1.9 \%$ and the number of positive samples normalized, these values were significantly higher in relation to the parameters before treatment $(\mathrm{P}<0.001)$ and the control group $(\mathrm{P}<0.05$. $)$. However, at the FN of neutrophils derived indicators have not changed significantly in the first group of patients throughout the study and the number of positive samples in 30 days was equal to $26.1 \%$.

Application of FarGALS drug in the patients of the main group led to the activation performance of lysozyme and sIgA content in the saliva of patients. At the patients aged 40 to 59 years, baseline activity of lysozyme and sIgA were 19.0 $+0,46 \mathrm{mg} / \mathrm{ml}$ and $199+6.0 \mathrm{~g} / 1$, whereas after use of FarGALS preparation for rinsing the mouth lysozyme activity and sIgAincreased sharply and correspondingly was $32.2+$ $0.9 \mathrm{mg} / \mathrm{ml}$ and $302+7.5 \mu \mathrm{g} / 1$, the differences were statistically significant compared to the initial values of the control groups $(\mathrm{P}<0.001)$, respectively. The NWP indicators also normalized. After adaptation to removable dentures by 30 th day, these indicators came close to the initial indicators. 
Journal of research in health science. 2018; 1 (2): 60-66.

At the patients from 60 years to 74 FAN content and lysozyme before and after using traditional mouthwash increased after 15 days, respectively, was 48,5 \pm $0,78 \%$ and $51.9 \pm 1.1 \% ; 17.3 \pm 0.53$ and $22.7 \pm 0.83 \mathrm{mg} / \mathrm{ml}(\mathrm{P}<0.05$ and $\mathrm{P}$ $<0.001)$, the differences are statistically significant (Table 4.). NWP was $20.9 \%$ and $13.9 \%$ in the group. It revealed significant shifts reliable indicators from the FF and SIgA oral cavity after 15 days
(P> 0.05), respectively, and found significantly higher NWP $(27.9 \%$ and $30.2 \%$ ). in other words, after 15 days at 43/13patients local immunity of the oral cavity In the 2nd group after using the traditional mouth rinse is weakened.

The level of local immunity in the mixed saliva of the patients of the group 2 (60 to 74 years) in orthopedic treatment in the dynamics.

Table 2.

\begin{tabular}{|c|c|c|c|c|}
\hline No. & Indicators & Baselines & 15 daysaftertreatment & 30 daysaftertreatment \\
\hline \multirow{4}{*}{ Controlgroup } & FAN in $\%$ & $48.5 \pm 0.78$ & $51.9 \pm 1.1 *$ & $45.2 \pm 1.31 * .$. \\
\hline & $\overline{\mathrm{FH}}$ & $3.68 \pm 0.07$ & $3.92 \pm 0.12 *$ & $2.81 \pm 0.17 * * \bullet$ \\
\hline & $\begin{array}{c}\text { Lysozyme } \\
\mathrm{mg} / \mathrm{ml}\end{array}$ & $17.3 \pm 0.53$ & $22.7 \pm 0.83 * *$ & $15.6 \pm 0.75 \bullet$ \\
\hline & $\mathrm{SIgA \mu g} / 1$ & $180 \pm 8.9$ & $200 \pm 5.8$ & $167 \pm 4.56 \bullet \bullet$ \\
\hline \multirow{4}{*}{$\begin{array}{l}\text { Basic } \\
\text { Group }\end{array}$} & FAN in $\%$ & $48.5 \pm 0.78$ & $55.1 \pm 1.2 * * 0$ & $49.7 \pm 1.9 \bullet$ \\
\hline & FH & $3.68 \pm 0.07$ & $4.12 \pm 0.13 * *$ & $3.76 \pm 0.09 \bullet^{\circ \circ}$ \\
\hline & $\begin{array}{l}\text { Lysozyme } \\
\mathrm{mg} / \mathrm{ml}\end{array}$ & $17.3 \pm 0.53$ & $25.7 \pm 0.88 * *$ o & $19.6 \pm 0.57 \bullet \mathrm{oo}^{\circ}$ \\
\hline & SIgA $\mu \mathrm{g} / 1$ & $180 \pm 8.9$ & $238 \pm 4.5 * *$ o o & $192 \pm 5.6 \bullet^{\circ} \circ \mathrm{o}$ \\
\hline
\end{tabular}

Note: The reliability of differences from baseline $(* *-\mathrm{P}<0.001$ and $*-\mathrm{P}<0.05)$; Data from 15 days $(\bullet \bullet-\mathrm{P}<0.001 \bullet-\mathrm{P}<0.05)$ and control data $\left({ }^{\circ}{ }^{\circ}-\mathrm{P}<0.001{ }^{\circ}-\mathrm{P}<0.05\right)$.

As shown by the results of studies (table 2) after 30 days of continuous use of complete removable dentures, despite the fact that patients regularly rinsed the mouth and dentures with conventional rinse oral fluid, a significant decrease in the level sIgA- $12.1 \%$, reduced lysozyme activity $-11.7 \%$, FAH $-15.8 \%$, and the FF of $21.7 \%$ in saliva are reported compared with the control data.

At patients of the main groups by rinsing oral cavity and processing complete dentures with "FarGALS" positive local immunity changes are marked.After 15 days after the professional oral hygiene and the processing of dentures with "FarGALS" thelevel of local immunity (FAN, the FF, lysozyme and $\operatorname{sIg} \mathrm{A}$ ) in all patients was increased. And correspondingly, the average indices for the group was $55.1 \pm$ $1.1 \% ; 4.12 \pm 0.13 ; 25,7 \pm 0,88 \mathrm{mg} / \mathrm{ml}$ and $238 \pm 4,5 \mathrm{mkg} / 1$, the differences are statistically significant $(\mathrm{P}<0.001)$, respectively, with the baseline level. And the number of positive probes was only for the FAN and FP indicators $11.6 \%$. With other words $88.4 \%$ of the surveyed subjects normalized. We also note that on the 15th day of the study, the local immunity indices (FAN, FCH, lysozyme and $\operatorname{sIgA}$ ) in patients within the 2-group (from 60 to 74 years) were significantly higher in comparison with the indices of 
Akbarov A.N., Dadabaeva M.U., Usmanxodjayeva D.R. Clinical and immunological evaluation of efficacy of use in the dynamics of topical application of FarGALS in patients in the process of adaptation to complete removable plate prosthesis depending on age

patients in group $1(\mathrm{P}<0.05, \mathrm{P}<0.05$, $\mathrm{P}<0.001$ and $\mathrm{P}<0.001)$, respectively. On the 30th day, these indicators decreased and were within the initial values.

Indices of local immunity (FAN, $\mathrm{FCH}$, lysozyme and SIgA) in patients of senile age (from 75 to 90 years) with orthopedic treatment in dynamics are given in Table 3.

Level of content of local immunity parameters in mixed saliva in patients of Group 3 (from 75 to 90 years) with orthopedic treatment in dynamics.

Table 3.

\begin{tabular}{|c|c|c|c|c|}
\hline No. & Indicators & Baselines & 15 daysaftertreatment & 30 daysaftertreatment \\
\hline \multirow{4}{*}{ Control } & FAN in $\%$ & $45.5 \pm 0.90$ & $47.1 \pm 1.21$ & $41.0 \pm 1.85 * \bullet$ \\
\hline & $\overline{\mathrm{FH}}$ & $3.23 \pm 0.1$ & $3.61 \pm 0.13 *$ & $2.75 \pm 0.18 * . \bullet$ \\
\hline & Lysozymemg / ml & $16.6 \pm 0.53$ & $20.3 \pm 0.39 * *$ & $14.5 \pm 0.78 * \bullet \cdot$ \\
\hline & SIgA $\mu \mathrm{g} / 1$ & $169 \pm 3.2$ & $185 \pm 8.3$ & $156 \pm 4.2 \bullet$ \\
\hline \multirow{4}{*}{ Basic } & FAN in $\%$ & $45.5 \pm 0.90$ & $51.9 \pm 1.51 * * 0$ & $46.1 \pm 1.41 \bullet^{\circ}$ \\
\hline & $\mathrm{FH}$ & $3.23 \pm 0.1$ & $3.94 \pm 0.12 * * 0$ & $3.76 \pm 0.17^{\circ 0}$ \\
\hline & Lysozymemg / ml & $16.6 \pm 0.53$ & $21.7 \pm 0.52 * * 0$ & $17.5 \pm 0.81 \bullet^{\circ}{ }^{\circ}$ \\
\hline & SIgA $\mu g / 1$ & $169 \pm 3.2$ & $196 \pm 5.2 *$ & $167 \pm 4.7 \bullet \bullet$ \\
\hline
\end{tabular}

Note: The reliability of differences from baseline $(* *-\mathrm{P}<0.001$ and $*-\mathrm{P}<0.05)$; Data from 15 days $(\bullet \bullet-\mathrm{P}<0.001 \bullet-\mathrm{P}<0.05)$ and control data $\left({ }^{\circ}{ }^{\circ}-\mathrm{P}<0.001^{\circ}-\mathrm{P}<0.05\right)$.

As can be seen from the data given in Table 3 in patients of group 3 (from 75 to 90 years), after traditional therapy (with the processing of removable prostheses and rinsing the oral cavity) on the side of local immunity, the heterogeneous responses of FAN, lysozyme and sIgA were observed on the 15th day of the study . It can be seen from the table that in all patients only the indices of FC and lysozyme increased insignificantly. And accordingly, the average indices for the group were $3.23 \pm 0.1$ and $16.6 \pm 0.53$ $\mathrm{mg} / \mathrm{ml}$ and above $3.61 \pm 0.13$ and 20.3 $\pm 0.39 \mathrm{mg} / \mathrm{ml}$, the differences are statistically significant in comparison with initial indices $(\mathrm{P}<0.05$ and $\mathrm{P}<0.001)$. With NWP decreased by $54.8 \%$ and 32.9 to 35.4 and $18.3 \%$. From the side indicators FAN and sIgA on the 15 day study significant positive changes in comparison Baseline not detected ( $\mathrm{P}>0.05)$, respectively. In the course of traditional treatment on the 30th day of the study, the local immunity indices significantly decreased in comparison with the baseline and control group parameters $(\mathrm{P}<0.001)$ and a sharp increase in NWP to (48.8, $57.3,46.3$ and $51.2 \%$ ), respectively were observed. Apparently, with the aging of the organism and the insufficiency of individual links of nonspecific immunity and the weakness of the controlling parts of the immune system in patients of senile age, a sharp decrease in the response of local immunity to the inflammatory process of the oral cavity occurred after removal of removable prostheses.

In patients of senile age, the main groups when treating the oral cavity and rinsing complete removable dentures with FarGALS, a positive shift of changes in local immunity is noted 15 days after orthopedic treatment. The level of local immunity (FAN, FCH, lysozyme and sIgA) in all patients significantly increased 
Journal of research in health science. 2018; 1 (2): 60-66.

( $\mathrm{P}<0.001)$, respectively, compared with baseline. Moreover, the number of positive probes also decreased and amounted to an average of the group $(26.6,35.6,24.4$ and $31.1 \%)$. In other words, in $2 / 3$ of the patients after the treatment, local immunity parameters were restored. After adaptation to removable dentures by 30th day, these indicators approached the initial values.

Thus, when studying the dynamics of the values (FAN, FCH, lysozyme and sIgA) of these indices, it was shown that in patients in the main group, after the use of the FarGALS drug in orthopedic practice, there was a significant increase, in contrast to the comparison group, local immunity in all examined groups, which suggested a positive effect of FarGALS on local immunity. Despite extremely unfavorable conditions for the functioning of the tissues of the prosthetic bed, the use of FarGALSresulted in positive effects, that led to the preservation of the initial level of local immunity and the clinical effect after the application of prostheses. Whereas with traditional orthopedic treatment, this indicator significantly worsened after the application of prostheses, with further aggravation of this negative effect over time. It should be noted that the most pronounced differences between the patients of the observation and comparison groups were noted in the early period, that is, up to 15 days of treatment. An increase in the local immunity index indicates the activation of nonspecific immune defense of the oral cavity in patients of the main group. The increase in FAN and FF indicates a response to pathogenic microorganisms, which are noted in patients with complete absence of teeth. FAN and FF in the observed patients of the main group decreased by 30th day, which indicates the relief of inflammation.

In our opinion, antibacterial and antiinflammatory properties of the drug FarGALS directed against the risk of pathogen attachment and appearance of inflammation in the oral cavity. As a result, optimal conditions are created to stimulate the activity of neutrophilic leukocytes and macrophages, which leads to the destruction of pathogens of inflammatory surfaces, intensive filling of the mucosal defect. The absence of an irritant effect on the mucous retains its integrity.The intact mucosa, especially the tissues of the prosthetic bed, is an important source of the epithelial layer covering erosion: the microenvironment activates a sufficient number of viable cells that activate healing, thereby guaranteeing the preservation of the oral microbiocenosis. 
Akbarov A.N., Dadabaeva M.U., Usmanxodjayeva D.R. Clinical and immunological evaluation of efficacy of use in the dynamics of topical application of FarGALS in patients in the process of adaptation to complete removable plate prosthesis depending on age

\section{References}

1. Takahashi Y., Yoshida A., Nagayoshi M., Kitamura C., Nishihara T., Awano S., Ansai T. Enumeration of viable Enterococcus faecalis, a predominant apical periodontitis pathogen, using propidium monoazide and quantitative real - time polymerase chain reaction // Microbiol. Immunol. - 2011. - N13. - P.889-892. 2. Teitelbaum S.L., Ross F.P. Genetic regulation of osteoclast development and function // Nat. Rev. Genet. - 2003. - Vol.4. - P.638 - 649.

3. Teles F.R., Teles R.P., Sachdeo A., Uzel N.G., Song X.Q., Torresyap G., Comparison of microbial changes in early redeveloping biofilms on natural teeth and dentures // Periodontol. - 2012. - Vol.83, N9. - P.1139 - 1148.

4. The isolation, identification and molecular analysis of Candida spp. isolated from the oral cavities of patients with diabetes mellitus // Oral Microbiol Immunol. - 2002. - Vol. 17. - № 3. - P. 181 - 185.

5. Tolentino Ede S., Chinellato L.E., Tarzia O.J. Saliva and tongue coating $\mathrm{pH}$ before and after use of mouthwashes and relationship with parameters of halitosis // Appl Oral Sci.- 2011.- Vol.19, N2.P.90 - 94.

6. Tolentino Ede S., Chinellato L.E., Tarzia O.J. Saliva and tongue coating $\mathrm{pH}$ before and after use of mouthwashes and relationship with parameters of halitosis // Appl.Oral Sci.- 2011.- Vol.19, N2. P. 90 - 94.

7. United Nations. Problems of the Elderly and the Aged. Draft Program and Arrangements for the World Assembly on the Elderly: Report of the Secretary - General. - New York, 1980. 